\title{
Influence of density and nickel content on fatigue strength of powder-forged gears - Comparison with ingot steel and sintered steel -
}

\author{
Masanori SEKI* and Masahiro FUJII** \\ *Department of Mechanical Systems Engineering, Okayama University of Science \\ 1-1, Ridai-cho, Kita-ku, Okayama 700-0005, Japan \\ E-mail: seki@mech.ous.ac.jp \\ **Department of Mechanical and Systems Engineering, Okayama University \\ 3-1-1, Tsushima-naka, Kita-ku, Okayama 700-8530, Japan
}

Received: 5 April 2017; Revised: 26 June 2017; Accepted: 28 June 2017

\begin{abstract}
In this study, sintered and powder-forged rollers and gears with different densities and nickel contents were fatigue-tested using a roller testing machine and a gear testing machine in order to elucidate their fatigue strength. The densities of the sintered and powder-forged rollers and gears were in the range $7.01 \mathrm{~g} / \mathrm{cm}^{3}$ to 7.84 $\mathrm{g} / \mathrm{cm}^{3}$, and the nickel contents of the metal powders were chosen as $0.5 \%$ and $3.0 \%$. These experimental results were compared with the results for ingot steel ones. The hardness near the surface of the test specimens with a nickel content of $3.0 \%$ was lower than that of the other ones. The pores in the sintered rollers became smaller or disappeared upon hot forging. The failure modes of the rollers and gears were mainly spalling due to subsurface cracking and pitting due to surface cracking, respectively. The fatigue strength of the sintered rollers and gears was the lowest in this experimental range. The fatigue strength of the powder-forged rollers and gears was roughly equivalent to that of the ingot steel ones, respectively. The fatigue strength of the test specimens increased as their density increased. It was clear that the fatigue strength of the sintered and powder-forged rollers and gears was proportional to the hardness at the failure depth for nickel contents of $0.5 \%$ and $3.0 \%$. In other words, the fatigue strength of the rollers and gears with a nickel content of $3.0 \%$ was similar to those of the others because of the toughness effect of nickel under the same material density.
\end{abstract}

Keywords : Gear, Sintering, Powder forging, Fatigue strength, Density, Nickel content

\section{Introduction}

Powder sintering is a process of compacting and forming metal powders under heat and pressure, while powder forging refers to hot forging after powder sintering. Both these processes can lead to a near net shape, where the initial shape of parts is very close to the final shape, and a net shape, where the initial and final shapes of the parts are identical ( $\mathrm{Li}$ et al., 2016). In addition, these processes allow for the production of large amounts of same-shaped parts and high-precision parts using a high-precision mold. However, the parts produced by these methods have a disadvantage in terms of strength, because the densities of the sintered and powder-forged materials are lower than the real density of ingot steel (Yamanaka et al., 2010). For this reason, much research has been carried out on the fatigue strength of sintered and powder-forged gears.

The bending fatigue strength of surface-densified sintered gears has been reported to become higher than that of ingot steel gears. Moreover, the bending fatigue strength of sintered gears increases with increasing sintered density (Engström et al., 2006). Other studies indicate that the rolling contact fatigue life of powder-forged rollers is similar to that of surface-densified sintered rollers (Jandeska et al., 2006). The load bearing capacity of high-density sintered gears with surface densification is also reported to be comparable to that of carburized ingot steel gear (Koide et al., 2011). However, to the best of our knowledge, research focusing on the influence of both density and nickel content on 
the fatigue strength of sintered and powder-forged gears has not been performed till date.

In this study, therefore, the rollers and gears were made of sintered materials and powder-forged materials with different densities and nickel contents. Then, rolling contact fatigue tests on the rollers and operating fatigue tests on the gears were performed in order to investigate the influence of density and nickel content on the fatigue strength of the sintered and powder-forged gears. For comparison, ingot steel rollers and gears were also fatigue-tested.

\section{Test specimens}

The manufacturing conditions for the sintered and powder-forged rollers and gears are given in Table 1. Two kinds of metal powder types were employed in this study. One type had a nickel content of $0.5 \%$ for conventional powder forging, and the other had a nickel content of $3.0 \%$ for the newly developed powder forging. Two kinds of pre-alloyed metal powders were sintered and powder-forged into discs. The green density of the sintered discs was $7.01 \mathrm{~g} / \mathrm{cm}^{3}$ and $7.04 \mathrm{~g} / \mathrm{cm}^{3}$, and the forging density of the powder-forged discs was $7.50 \mathrm{~g} / \mathrm{cm}^{3}$ and $7.84 \mathrm{~g} / \mathrm{cm}^{3}$. The above discs were manufactured to the test roller and pinion, as shown in Table 1 . Specimens $1 \mathrm{~N}$ and $2 \mathrm{~N}$ indicate nickel contents of $0.5 \%$ and $3.0 \%$, respectively. The numbers 70,75 , and 78 indicate the densities of the test specimens.

Table 1 Manufacturing conditions for test rollers and pinions.

\begin{tabular}{|c|c|c|c|c|c|c|c|c|c|c|}
\hline & \multirow{2}{*}{ Specimen } & \multicolumn{4}{|c|}{ Test roller } & \multicolumn{5}{|c|}{ Test pinion } \\
\hline & & R-1N70 & R-1N75 & R-1N78 & \multirow{2}{*}{$\frac{\mathrm{R}-2 \mathrm{~N} 78}{3.0 \% \mathrm{Ni}}$} & \multirow{2}{*}{$\frac{\mathrm{G}-1 \mathrm{~N} 70}{20.5 \% \mathrm{Ni}}$} & \multirow{2}{*}{\multicolumn{2}{|c|}{\begin{tabular}{c|c} 
G-2N70 & G-2N75 \\
$3.0 \% \mathrm{Ni}$
\end{tabular}}} & \multirow{2}{*}{$\frac{\mathrm{G}-1 \mathrm{~N} 78}{20.5 \% \mathrm{Ni}}$} & \multirow{2}{*}{$\frac{\mathrm{G}-2 \mathrm{~N} 78}{3.0 \% \mathrm{Ni}}$} \\
\hline \multirow{7}{*}{ Sintering } & \multirow{2}{*}{ Metal powder type } & \multicolumn{3}{|c|}{$0.5 \% \mathrm{Ni}$} & & & & & & \\
\hline & & \multicolumn{9}{|c|}{$0.2 \% \mathrm{C}, 0.2 \% \mathrm{Mn}, 1.0 \% \mathrm{Mo}$, Balance Fe } \\
\hline & Particle diameter & \multicolumn{9}{|c|}{ Average $75 \mu \mathrm{m}$, Maximum $250 \mu \mathrm{m}$} \\
\hline & Mixing & \multicolumn{9}{|c|}{$0.20 \%$ Graphite, $0.75 \%$ Zinc stearate } \\
\hline & Compacting pressure & \multicolumn{9}{|c|}{$6.5 \mathrm{ton} / \mathrm{cm}^{2}$} \\
\hline & Green density & $7.01 \mathrm{~g} / \mathrm{cm}^{3}$ & $6.89 \mathrm{~g} / \mathrm{cm}^{3}$ & $6.89 \mathrm{~g} / \mathrm{cm}^{3}$ & $6.72 \mathrm{~g} / \mathrm{cm}^{3}$ & $7.01 \mathrm{~g} / \mathrm{cm}^{3}$ & $7.04 \mathrm{~g} / \mathrm{cm}^{3}$ & $6.92 \mathrm{~g} / \mathrm{cm}^{3}$ & $7.12 \mathrm{~g} / \mathrm{cm}^{3}$ & $6.92 \mathrm{~g} / \mathrm{cm}^{3}$ \\
\hline & Heat treatment & \multicolumn{9}{|c|}{$1403 \mathrm{~K} \times 20 \mathrm{~min}$, in $\mathrm{N}_{2}$ gas } \\
\hline \multirow{3}{*}{ Forging } & Compacting pressure & \multirow{3}{*}{ N/A } & $2.7 \mathrm{ton} / \mathrm{cm}^{2}$ & \multicolumn{2}{|c|}{10.0 ton $/ \mathrm{cm}^{2}$} & \multirow{3}{*}{\multicolumn{2}{|c|}{$\mathrm{N} / \mathrm{A}$}} & $2.7 \mathrm{ton} / \mathrm{cm}^{2}$ & \multicolumn{2}{|c|}{10.0 ton $/ \mathrm{cm}^{2}$} \\
\hline & Forging density & & $7.50 \mathrm{~g} / \mathrm{cm}^{3}$ & \multicolumn{2}{|c|}{$7.84 \mathrm{~g} / \mathrm{cm}^{3}$} & & & $7.50 \mathrm{~g} / \mathrm{cm}^{3}$ & \multicolumn{2}{|c|}{$7.84 \mathrm{~g} / \mathrm{cm}^{3}$} \\
\hline & Heat treatment & & \multicolumn{3}{|c|}{$1323 \mathrm{~K} \times 30 \mathrm{~min}$, in $\mathrm{N}_{2}$ gas } & & & \multicolumn{3}{|c|}{$1323 \mathrm{~K} \times 30 \mathrm{~min}$, in $\mathrm{N}_{2}$ gas } \\
\hline \multicolumn{2}{|r|}{ Machining } & \multicolumn{4}{|c|}{ Turning } & \multicolumn{5}{|c|}{ Hobbing, Turning } \\
\hline \multicolumn{2}{|c|}{ Case hardnening } & \multicolumn{9}{|c|}{$1213 \mathrm{~K}$, Oil cooling } \\
\hline \multicolumn{2}{|c|}{ Case hardnening time } & $3.5 \mathrm{hr}$ & $4.5 \mathrm{hr}$ & \multicolumn{2}{|c|}{$8.0 \mathrm{hr}$} & \multicolumn{2}{|c|}{$3.5 \mathrm{hr}$} & $4.5 \mathrm{hr}$ & \multicolumn{2}{|c|}{$8.0 \mathrm{hr}$} \\
\hline \multicolumn{2}{|r|}{ Tempering } & & & & $453 \mathrm{~K}$ & x $1.5 \mathrm{hr}$, Air & ooling & & & \\
\hline & Finishing & & & & & Grinding & & & & \\
\hline
\end{tabular}

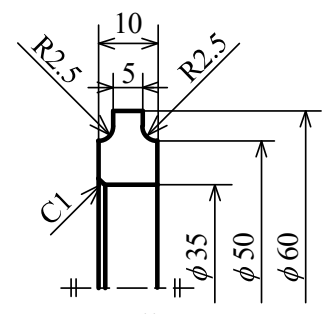

Test roller

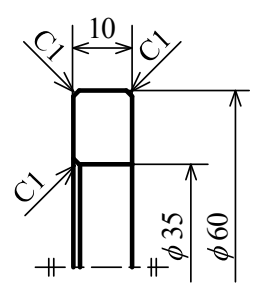

Mating roller
Fig.1 Shapes and dimensions of test roller pair.

Table 2 Specifications of test gear pair.

\begin{tabular}{lc|c|c}
\hline & Pinion & Gear \\
\hline Module mm & \multicolumn{2}{|c}{4} \\
\hline Pressure angle deg. & \multicolumn{2}{|c}{20} \\
\hline Number of teeth & 19 & 26 \\
\hline $\begin{array}{l}\text { Addendum modification } \\
\text { coefficient }\end{array}$ & 0 & 0.2916 \\
\hline Tip circle diameter $\mathrm{mm}$ & 84.67 & 115.00 \\
\hline Center distance $\mathrm{mm}$ & \multicolumn{2}{|c}{91.5} \\
\hline Facewidth & \multicolumn{2}{|c}{1.535} \\
\hline Contact ratio & \multicolumn{2}{|c}{ Class 2 } & Class 2 \\
\hline Accuracy* & \multicolumn{2}{|c}{ Case hardening } \\
\hline Heat treatment & \multicolumn{2}{|c}{ Grinding } \\
\hline Tooth surface finishing & \multicolumn{3}{|c}{5} \\
\hline *JIS B 1702 -1976 &
\end{tabular}

The test roller pair with $60 \mathrm{~mm}$ diameter shown in Fig. 1 and the spur gear pair shown in Table 2 were employed in this study. The test gear pair had involute profile teeth, a module of $4 \mathrm{~mm}$ and a standard pressure angle of $20 \mathrm{deg}$. All the sintered and powder-forged test rollers and pinions were finish-ground after case hardening. In order to compare the 
fatigue strength of these specimens with that of the ingot steel specimens, ingot steel rollers and pinions were also employed. The test rollers were made of chromium molybdenum steel (JIS: SCM420) and chromium steel (JIS: SCr420), and the test pinions were made of chromium molybdenum steel (JIS: SCM415). All the mating rollers and gears were made of chromium molybdenum steel (JIS: SCM415), and were finish-ground after case hardening.

Young's modulus and Poisson's ratio of the sintered rollers and pinions were $152 \mathrm{GPa}$ and 0.26 , respectively. The corresponding values for the powder-forged samples with a forging density of $7.50 \mathrm{~g} / \mathrm{cm}^{3}$ were $177 \mathrm{GPa}$ and 0.28 , and powder-forged samples with a forging density of $7.84 \mathrm{~g} / \mathrm{cm}^{3}$, ingot steel samples are $206 \mathrm{GPa}$ and 0.30 .

Figure 2 shows the average hardness distributions of the test rollers and pinions. The Vickers hardness was measured with a micro hardness tester under a measuring load of $0.98 \mathrm{~N}$ for $30 \mathrm{~s}$. The average hardness distribution was obtained from five measured hardness values at each depth below the circumferential surface of the roller. The hardness values of the test pinions were measured at the working pitch point along the normal direction to the tooth surface. The hardened layers of the sintered roller and pinions were deeper than those of the others, since carbon monoxide gas was deeply into the sintered roller and pinions through the pores. Nickel generally increases toughness, ductility, and hardenability, and promotes the formation of an austenitic structure. Additionally, the material with higher nickel content tends to have higher retained austenite content. The hardness of retained austenite is lower than that of martensitic structure (Stephenson et al., 2004). As shown in this figure, the hardness near the surface of the test roller and pinions with a nickel content of $3.0 \%$ was lower than that of the other rollers and pinions.

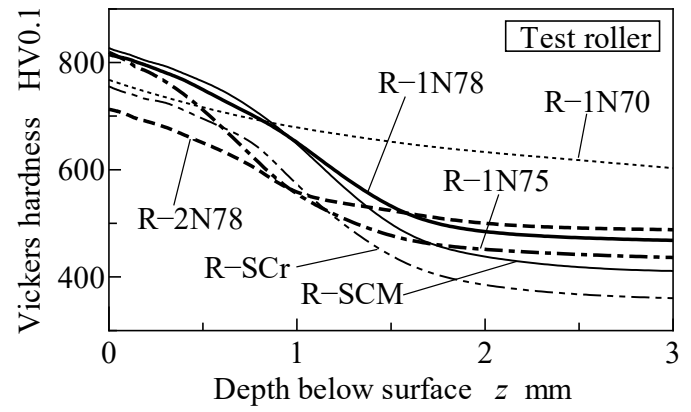

(a) Test rollers

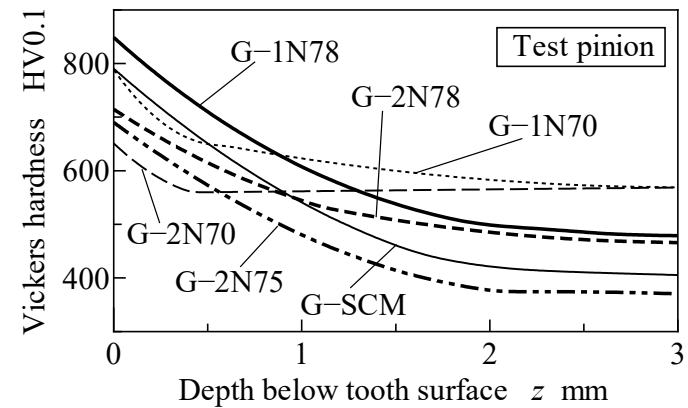

(b) Test pinions

Fig.2 Hardness distributions of test rollers and pinions. In both cases, the hardness near the surface of the test specimens with a nickel content of $3.0 \%$ was lower than that of the other test specimens.

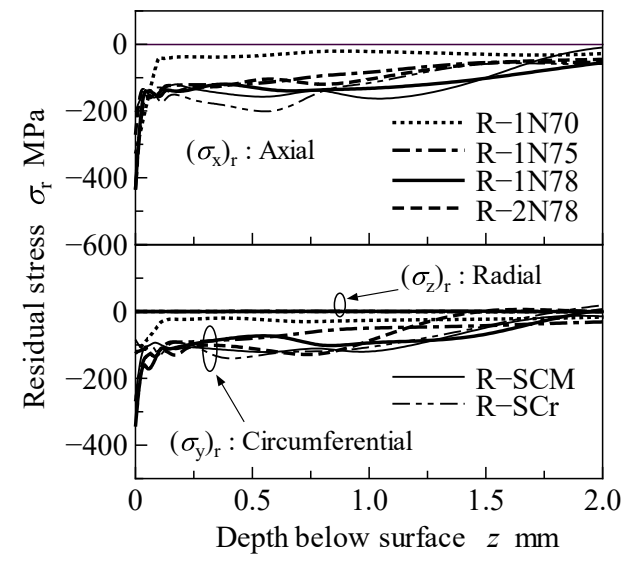

Fig.3 Residual stress distributions of test rollers. The residual stress distributions of all the test rollers except for the sintered test roller were almost the same in this study. The residual stress of the sintered test roller was close to zero below the roller surface.

The residual stress distributions of the test rollers are shown in Fig.3. The residual stress was measured according to the $2 \theta-\sin ^{2} \psi$ method (The Society of Materials Science, 1982) using CrK $\alpha$ radiation as characteristic X-ray. For stress analysis below the contact roller surface, an arbitrary point at the center of the roller surface was chosen as the origin, and the $x, y$, and $z$ coordinates were set in the axial, circumferential, and radial directions of the roller, 
respectively. The surface layer of the roller was removed by electrolytic polishing to measure the residual stress below the roller surface. The residual stresses $\left(\sigma_{\mathrm{x}}\right)_{\mathrm{r}}$ and $\left(\sigma_{\mathrm{y}}\right)_{\mathrm{r}}$ in the axial and circumferential directions of the roller, shown in Fig.3, were determined by modifying the measured residual stresses by the elastic calculation (Yonetani, 1969), since the measured stresses were influenced by the removal of the surface layer. The residual stress $\left(\sigma_{\mathrm{z}}\right)_{\mathrm{r}}$ in the radial direction of the roller was determined by the elastic equations (Yonetani, 1969). The residual stress distributions of all the test rollers except for R-1N70 were almost the same in this study. The residual stress of R-1N70 was close to zero below the roller surface.

Table 3 shows the amount of retained austenite on the roller surfaces obtained by X-ray diffraction analysis using CrK $\alpha$ radiation (The Society of Materials Science, 1982). Comparison of R-1N78 with R-2N78 reveals that the amount of retained austenite is higher in the latter under the same forging density. This fact indicates that the hardness near the surface of the test specimens with a nickel content of $3.0 \%$ did not show any notable increase upon austenitizing, because of the presence of nickel.

Table 4 shows the surface properties of the test specimens. The surface hardness values of the rollers and gears were obtained from their hardness distributions shown in Fig.2. The surface residual stresses were measured in the same manner as depicted in Fig.3. In the case of the gear, the surface residual stresses $\left(\sigma_{\mathrm{x}}\right)_{\mathrm{r}}$ and $\left(\sigma_{\mathrm{y}}\right)_{\mathrm{r}}$ were measured at the working pitch point in the tooth trace and tooth profile directions, respectively. $R \mathrm{a}$ and $R z$ in Table 4 indicate the arithmetical mean roughness and maximum height roughness, respectively. The surface roughnesses $R \mathrm{a}$ and $R \mathrm{z}$ of the rollers were measured on the circumferential surface along the axial direction, and those of the gears were measured near the working pitch point along the tooth profile direction using a surface roughness meter. The density of the test specimens had little effect on their surface residual stress. The surface roughnesses of the test specimens were almost equal to each other, because of grind finishing.

Table 3 Amount of retained austenite on roller surfaces.

\begin{tabular}{c|c|c|c|c|c|c|c}
\hline Specimen & R-1N70 & R-1N75 & R-1N78 & R-2N78 & R-SCM & R-SCr & Mating roller \\
\hline$\left(V_{\gamma}\right)_{\mathrm{x}} \%$ & 21.77 & 26.62 & 27.87 & 31.07 & 40.19 & 33.72 & 39.11 \\
\hline$\left(V_{\gamma}\right)_{\mathrm{y}} \%$ & 21.49 & 25.51 & 26.14 & 30.23 & 39.85 & 32.74 & 38.76 \\
\hline
\end{tabular}

Table 4 Surface hardness, surface residual stress, and surface roughness of test specimens.

\begin{tabular}{|c|c|c|c|c|c|c|c|}
\hline Specimen & R-1N70 & R-1N75 & R-1N78 & R-2N78 & R-SCM & $\mathrm{R}-\mathrm{SCr}$ & Mating roller \\
\hline HV0.1 & 768 & 819 & 815 & 713 & 827 & 756 & 763 \\
\hline$\left(\sigma_{\mathrm{x}}\right)_{\mathrm{r}} \mathrm{MPa}$ & -328 & -434 & -436 & -271 & -413 & -203 & -402 \\
\hline$\left(\sigma_{\mathrm{y}}\right)_{\mathrm{r}} \mathrm{MPa}$ & -125 & -269 & -334 & -121 & -255 & -84 & -183 \\
\hline$R \mathrm{a} \quad \mu \mathrm{m}$ & 0.29 & 0.28 & 0.23 & 0.20 & 0.25 & 0.21 & 0.29 \\
\hline$R \mathrm{z} \quad \mu \mathrm{m}$ & 2.85 & 2.60 & 2.23 & 1.94 & 2.29 & 2.05 & 2.88 \\
\hline
\end{tabular}

\begin{tabular}{r|c|c|c|c|c|c|c}
\hline Specimen & G-1N70 & G-2N70 & G-2N75 & G-1N78 & G-2N78 & G-SCM & Mating gear \\
\hline $\mathrm{HV0.1}$ & 788 & 651 & 690 & 849 & 715 & 790 & 880 \\
\hline$\left(\sigma_{\mathrm{x}}\right)_{\mathrm{r}} \mathrm{MPa}$ & -110 & -145 & -151 & -224 & -157 & -344 & -165 \\
\hline$\left(\sigma_{\mathrm{y}}\right)_{\mathrm{r}} \mathrm{MPa}$ & -385 & -346 & -597 & -777 & -445 & -803 & -662 \\
\hline$R \mathrm{a} \mu \mathrm{m}$ & 0.26 & 0.22 & 0.25 & 0.24 & 0.19 & 0.23 & 0.23 \\
\hline$R \mathrm{z} \mu \mathrm{m}$ & 1.95 & 1.70 & 1.91 & 1.75 & 1.31 & 1.54 & 1.69 \\
\hline
\end{tabular}

Cross section photographs of the test rollers were recorded using a metallographic microscope (Fig.4). In this study, powder-forged specimens were produced by forging the sintered material at high temperature. It was confirmed from the microscopic observations that pores still existed in the powder-forged test rollers with a forging density of $7.50 \mathrm{~g} / \mathrm{cm}^{3}$. The porosity and circle equivalent diameter of the test rollers, obtained by binary image processing using an image analyzer, were $14.6 \%$ and $35.1 \mu \mathrm{m}$ for R-1N70, and $3.6 \%$ and $22.4 \mu \mathrm{m}$ for R-1N75. Pores could not be found in R-1N78 and R-2N78 with a forging density close to the real density of ingot steel. Thus, it can be considered that the pores disappeared upon hot forging and that the porosity of R-1N78 and R-2N78 was nearly $0 \%$. 


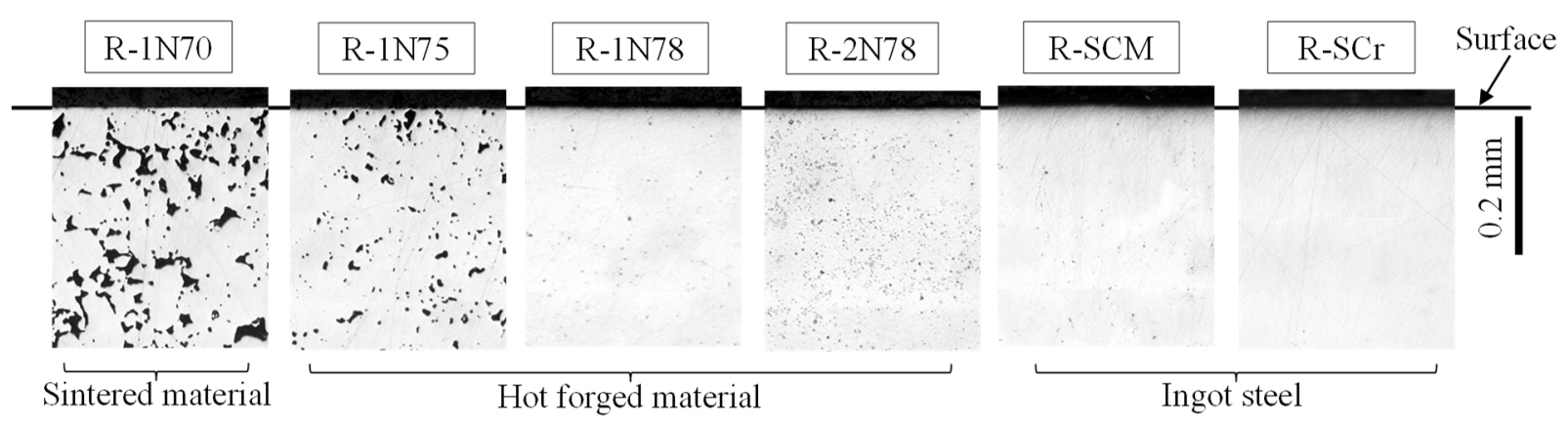

Fig.4 Cross sections of test rollers. Pores existing in the sintered material were diminished upon hot forging. In particular, the pores disappeared after hot forging under a compacting pressure, resulting in a forging density of $7.84 \mathrm{~g} / \mathrm{cm}^{3}$.

\section{Experimental procedures}

Rolling contact fatigue tests on the rollers were performed under sliding-rolling contact conditions using a spring-loading-type two-cylinder testing machine (Zhang et al., 2004). The circumferential velocity and specific sliding of the test roller were $4.50 \mathrm{~m} / \mathrm{s}$ and $-25.7 \%$, respectively, while the corresponding values for the mating roller were $5.65 \mathrm{~m} / \mathrm{s}$ and $+20.5 \%$. Operating fatigue tests on the gears were performed at a rotational speed of the test pinion of $1800 \mathrm{rpm}$ using a power circulating-type gear testing machine (Seki et al., 2007). The maximum Hertzian stress $p_{\max }$ (Johnson, 1987) on the roller surface and on the tooth flank at the working pitch point was adopted as the standard for loading between the contact surfaces.

The lubricating oil employed in the roller tests and gear tests was gear oil with extreme pressure additives. The properties of the lubricating oil are given in Table 5. The lubricating oil was pressure supplied to the engaging side of the roller pair and gear pair from nozzles. The flow rate of the supplied oil was about $1500 \mathrm{ml} / \mathrm{min}$ for the test roller pair and about $750 \mathrm{ml} / \mathrm{min}$ for the test gear pair. The oil temperature was adjusted to $313 \pm 4 \mathrm{~K}$.

Table 5 Properties of lubricating oil employed in roller tests and gear tests.

\begin{tabular}{|c|c|c|}
\hline & & Gear oil \\
\hline Specific gravity & $288 / 277 \mathrm{~K}$ & 0.9022 \\
\hline Flash point & $\mathrm{K}$ & 477 \\
\hline Pour point & $\mathrm{K}$ & 260.5 \\
\hline Kinematic viscosity & $313 \mathrm{~K}$ & 190.9 \\
\hline$\times 10^{-6} \mathrm{~m}^{2} / \mathrm{s}$ & $373 K$ & 17.74 \\
\hline Viscosity index & & 98 \\
\hline Total acid number & $\mathrm{mgKOH} / \mathrm{g}$ & 2.26 \\
\hline
\end{tabular}

As described later, rolling contact fatigue tests on the test rollers were performed under $p_{\max }$ of $900 \mathrm{MPa}$ to 2200 MPa. The minimum oil film thickness reported by Dowson (Dowson, 1967-1968), $h_{\min }$, was in the range $2.0 \mu \mathrm{m}$ to 2.5 $\mu \mathrm{m}$ for the test roller pair. In contrast, operating fatigue tests on the test pinions were performed under $p_{\max }$ of 1200 $\mathrm{MPa}$ to $2400 \mathrm{MPa}$, and $h_{\min }$ was in the range $0.9 \mu \mathrm{m}$ to $3.2 \mu \mathrm{m}$ for the test gear pair. The $D$ value defined by Dawson (Dawson, 1965-1966) was above 1 for all the test roller pairs and test gear pairs. In the calculations of $h_{\min }$ and $D$, the oil temperature between the contact surfaces was taken as $313 \mathrm{~K}$, which was the temperature of the supplied oil, in the fatigue tests.

The roller testing machine and gear testing machine automatically stopped when the vibration transducers fixed on the machines acted by vibration increase due to surface failure or tooth breakage. The fatigue life of the test rollers and pinions was defined as the total number of cycles when the percentage of pitted area in a test gear pair reached $1 \%$, or when the testing machine automatically stopped.

\section{Experimental results}

\subsection{Failure mode of test specimens}

Figures 5 and 6 show the photographs of the failed test rollers and pinions, respectively. Figure 5 shows that the 
failure mode of the test rollers was mainly the spalling due to subsurface cracking, as well as the pitting due to surface cracking in some cases. The failure mode of all the sintered test rollers was the spalling due to subsurface cracking. On the other hand, the failure mode of the powder-forged test pinions and the ingot steel test pinions was mainly the pitting due to surface cracking (Fig.6). For some test pinions fatigue-tested under higher load conditions in this experimental range, tooth breakage occurred due to pitting at the working pitch point and due to bending. For the sintered test pinions, the failure modes were mainly tooth breakage due to bending and pitting under lower load conditions.

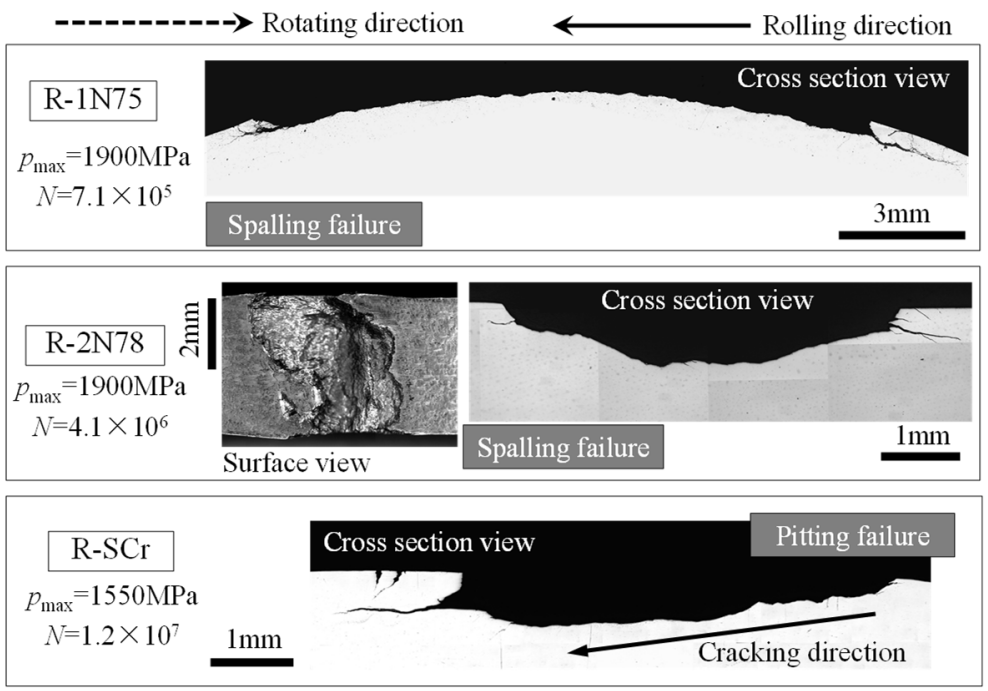

Fig.5 Observations of failed test rollers. The failure mode of the test rollers was mainly the spalling due to subsurface cracking, and pitting due to surface cracking in some cases.

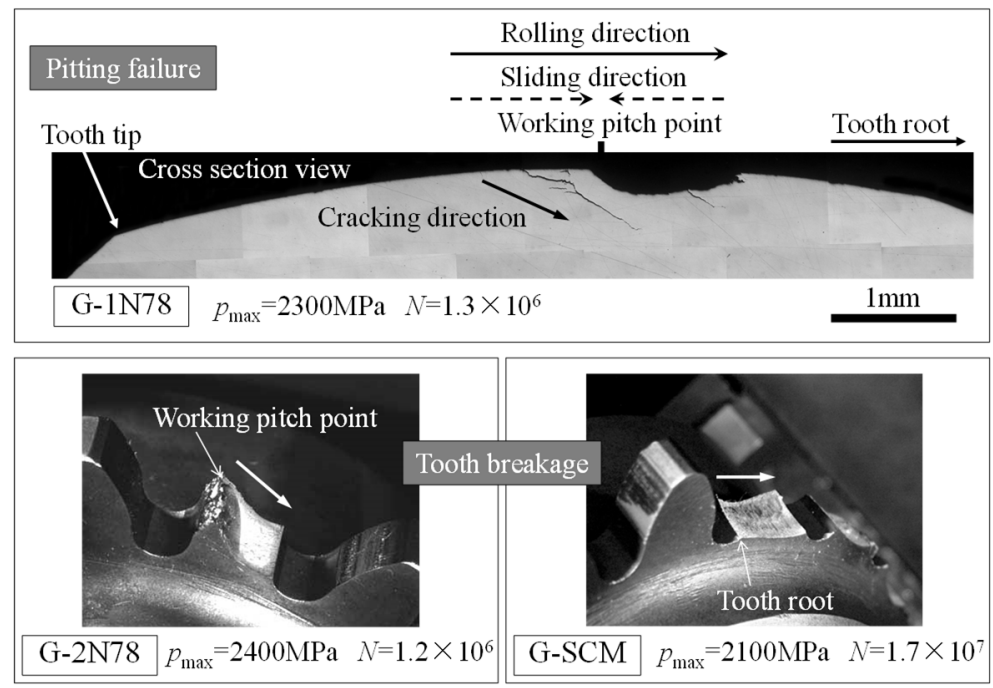

Fig.6 Observations of failed test pinions. The failure mode of the test pinions was mainly the pitting due to surface cracking. For some test pinions fatigue-tested under higher load conditions, tooth breakage occurred due to pitting at the working pitch point and due to bending.

\subsection{Fatigue life of test specimens}

Figures 7 and 8 show the relationships between the maximum Herztian stress $p_{\max }$ and the number of cycles to failure $N$ obtained by the roller tests and the gear tests, respectively. In these figures, the plots with arrows indicate that the failure did not occur until $2 \times 10^{7}$ cycles. These $p_{\max }-N$ curves were determined by the least squares method using the experimental plots of fatigue lives. The approximate curve for each test specimen was obtained by all the experimental plots except the ones with an arrow. The maximum bending stress at tooth root $\sigma_{\mathrm{BTmax}}$ shown in Fig.8 was calculated using the formula defined by Niemann and Glaubitz (Japan Society of Mechanical Engineers, 1979). These figures suggest that the fatigue lives of the test specimens were greatly increased by hot forging, because fatigue lives of the 
sintered test rollers and pinions were clearly shorter than those of the others. Under the higher load conditions in this experimental range, the fatigue lives of the powder-forged test rollers and pinions with a forging density of $7.84 \mathrm{~g} / \mathrm{cm}^{3}$ were longer than those of the ingot steel ones, while the test rollers and pinions powder-forged with a forging density of $7.50 \mathrm{~g} / \mathrm{cm}^{3}$ had shorter fatigue lives. On the other hand, under the lower load conditions, the fatigue lives of the ingot steel test rollers and pinions were the longest among all the test rollers and pinions. Thus, the pores and the inclusions in the sintered and powder-forged materials probably reduced the fatigue life in the long fatigue tests.

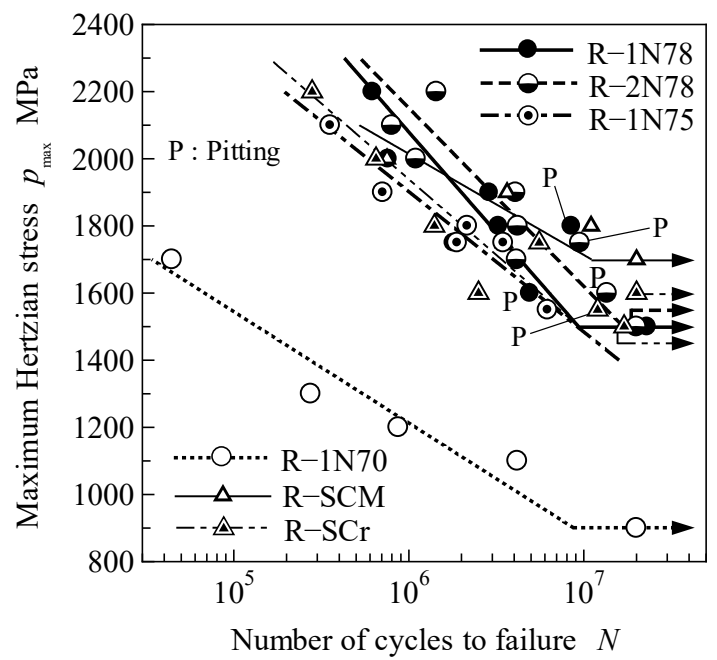

Fig.7 $p_{\max }-N$ curves of test rollers. The fatigue lives of the sintered test rollers were clearly shorter than those of the other test rollers. In other words, the fatigue lives of the test rollers were greatly increased by hot forging. Under the higher load conditions, the fatigue lives of the powder-forged test rollers with a forging density of $7.84 \mathrm{~g} / \mathrm{cm}^{3}$ were the longest among all the test rollers.

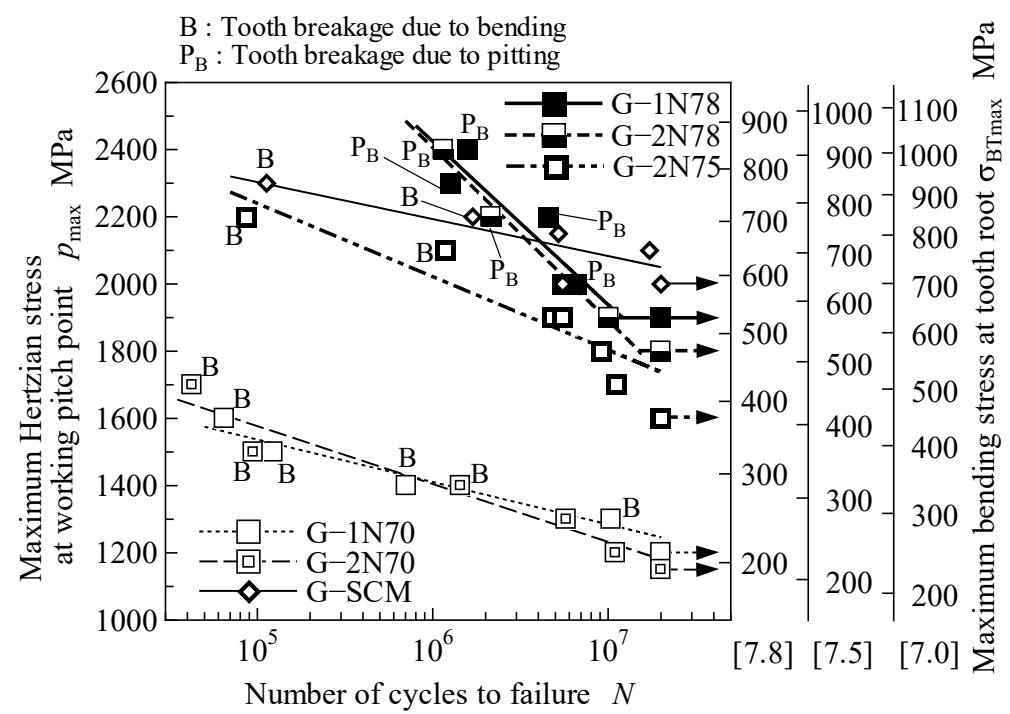

Fig.8 $p_{\max }-N$ curves of test pinions. As in Fig.7, the fatigue lives of the test pinions were also extremely increased by hot forging, and those of the powder-forged test pinions with a forging density of $7.84 \mathrm{~g} / \mathrm{cm}^{3}$ were the longest under the higher load conditions.

\subsection{Fatigue strength of test specimens}

Figure 9 shows the relationships between the fatigue strength and the density of the test rollers and pinions. In this study, the fatigue strength $\left(p_{\max }\right)_{\lim }$ of a test specimen was defined as the maximum Hertzian stress $p_{\max }$ after $2 \times 10^{7}$ cycles. Figure 9 shows that the $\left(p_{\max }\right)_{\text {lim }}$ of the test rollers and pinions increased with increasing density. In addition, the $\left(p_{\text {max }}\right)_{\text {lim }}$ values of the powder-forged test rollers and pinions were roughly equivalent to those of the ingot steel test rollers and pinions, respectively. The effect of the nickel content on the $\left(p_{\max }\right)_{\text {lim }}$ of the test specimen was not clear from 
Fig.9.

Generally, the rolling contact fatigue strength increased with decreasing relative radius of curvature (Yoshida et al., 1994). The fatigue strengths of the test pinions, with a relative radius of curvature of $8.5 \mathrm{~mm}$ at the working pitch point, were larger than those of the test rollers with a relative radius of curvature of $15.0 \mathrm{~mm}$ (Fig.9). The reasons for the difference in fatigue strength between the test rollers and pinions include the difference in failure modes between the test rollers and pinions, the influence of the dynamic load in tooth meshing, and the difference in the sliding-rolling contact conditions of the gear test and the roller test, i.e. the specific sliding on the tooth surface of the test pinion changed in tooth meshing while that on the test roller surface was constant.

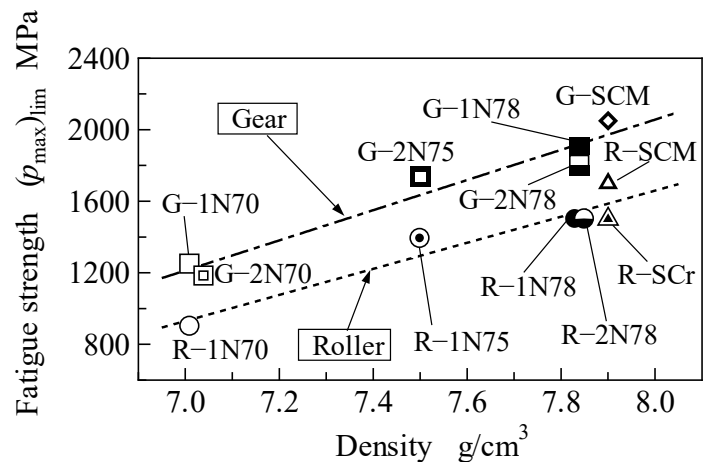

Fig.9 Relationships between fatigue strength and density of test rollers and pinions. The fatigue strengths of the test rollers and pinions increased with increasing density, while those of the powder-forged test rollers and pinions were similar to those of the respective ingot steel ones.

\subsection{Fatigue strength and hardness of test specimens}

As previously noted, the failure modes of the test rollers and pinions were mainly the spalling and pitting, respectively. The spalling failure was related to the maximum amplitude $\left[A\left(\tau_{\mathrm{yz}} / \mathrm{HV}\right)\right]_{\max }$ of the ratio of the alternating orthogonal shear stress $\tau_{\mathrm{yz}}$ to the Vickers hardness HV (Fujita and Yoshida, 1978), and the pitting failure was related to the maximum amplitude $\left[A\left(\sigma_{\mathrm{y}} / \mathrm{HV}\right)\right]_{\max }$ of the ratio of the tangential normal stress $\sigma_{\mathrm{y}}$ to the Vickers hardness $\mathrm{HV}$ (Fujita and Yoshida, 1979). In this study, the maximum amplitudes $\left[A\left(\tau_{\mathrm{yz}} / \mathrm{HV}\right)\right]_{\max }$ and $\left[A\left(\sigma_{\mathrm{y}} / \mathrm{HV}\right)\right]_{\max }$ were calculated by neglecting the effect of mean stress on fatigue and assuming that the material strength of the test specimens is proportional to their hardnesses before the fatigue tests. Therefore, the same theories using the amplitudes with alternating orthogonal shear stress and tangential normal stress were also applied to the test rollers and pinions employed in this study.

Alternating orthogonal shear stress $\tau_{\mathrm{yz}}$ and tangential normal stress $\sigma_{\mathrm{y}}$ on and below the contact surface were calculated using a reported analytical method by Smith (Smith and Liu, 1953). In the calculations of these stresses, a contact point on the roller surface or the tooth surface was chosen as the origin, the axial direction of the roller or the tooth trace direction of the pinion was chosen as the $x$ coordinate, the circumferential direction of the roller or the tooth profile direction of the pinion was chosen as the $y$ coordinate, and the radial direction of the roller or the normal direction to the tooth surface of the pinion was chosen as the $z$ coordinate. In this contact stress analysis, the friction coefficient between the test roller pair and the test gear pair was considered to be 0.035 , from previously reported experimental results of the case-hardened steel roller pair (Yoshida et al., 2003), because it was not measured herein. Moreover, the residual stress distribution of the test rollers shown in Fig.3 was considered for calculating the alternating orthogonal shear stress $\tau_{\mathrm{yz}}$, and the surface residual stress of the test pinions shown in Table 4 was considered for calculating the tangential normal stress $\sigma_{\mathrm{y}}$. The residual stress distribution below the tooth surface of the test pinions was not required in the calculation of the maximum amplitude $\left[A\left(\sigma_{\mathrm{y}} / \mathrm{HV}\right)\right]_{\max }$.

$\left[A\left(\tau_{\mathrm{yz}} / \mathrm{HV}\right)\right]_{\max }$ and $\left[A\left(\sigma_{\mathrm{y}} / \mathrm{HV}\right)\right]_{\max }$ were the maximum values of the amplitudes $A\left(\tau_{\mathrm{yz}} / \mathrm{HV}\right)$ and $A\left(\sigma_{\mathrm{y}} / \mathrm{HV}\right)$, respectively, for each depth value on and below the test specimen surface. In this study, the results of the fatigue tests confirmed that $A\left(\tau_{\mathrm{yz}} / \mathrm{HV}\right)$ became maximum at almost the same depth as the spalling failure depth, and $A\left(\sigma_{\mathrm{y}} / \mathrm{HV}\right)$ became maximum at the test specimen surface at which the pitting failure occurred.

The hardness distributions of the test specimens were greatly affected by the nickel content of the metal powders (Fig.2). Thus, the fatigue strengths of the test specimens were expected to depend on the hardness values of the test 
rollers at $\left[A\left(\tau_{\mathrm{yz}} / \mathrm{HV}\right)\right]_{\max }$ and the hardness values of the test pinions at $\left[A\left(\sigma_{\mathrm{y}} / \mathrm{HV}\right)\right]_{\max }$. Figure 10 shows that the fatigue strength $\left(p_{\max }\right)_{\text {lim }}$ of the test specimens was proportional to the hardness at the maximum amplitude for both nickel contents of $0.5 \%$ and $3.0 \%$. In other words, the $\left(p_{\max }\right)_{\text {lim }}$ of the test specimens increased with increasing hardness at the failure depth, indicating that the increase in hardness at the failure depth enhanced the $\left(p_{\max }\right)_{\lim }$ of the test specimens. Moreover, the hardness near the surface of the test specimens with a nickel content of $3.0 \%$ was lower than that of the other test specimens. However, it follows that the $\left(p_{\max }\right) \lim$ values of the test rollers and pinions with a nickel content of $3.0 \%$ were similar to those of the others because of the toughness effect of nickel under the same material density.

The fatigue strength of the powder-forged gears with a forging density of $7.84 \mathrm{~g} / \mathrm{cm}^{3}$ were roughly equivalent to that of the ingot steel one. Thus, the fatigue strengths of the powder-forged gears manufactured by near net shape and net shape were expected to be roughly equivalent to those of the ingot steel gears. Consequently, there is a good chance that the near net shape and net shape manufacture processes of powder-forged steel are helpful for efficiency improvement of the mass production in terms of the fatigue strength of steel gears. Figs. 9 and 10, however, show that the fatigue strengths of the powder-forged gears depend heavily on their forging density and hardness. Therefore, the near net shape and net shape manufacture processes should be selected for producing steel gears after carefully examining the forging density and hardness of the powder-forged steel.

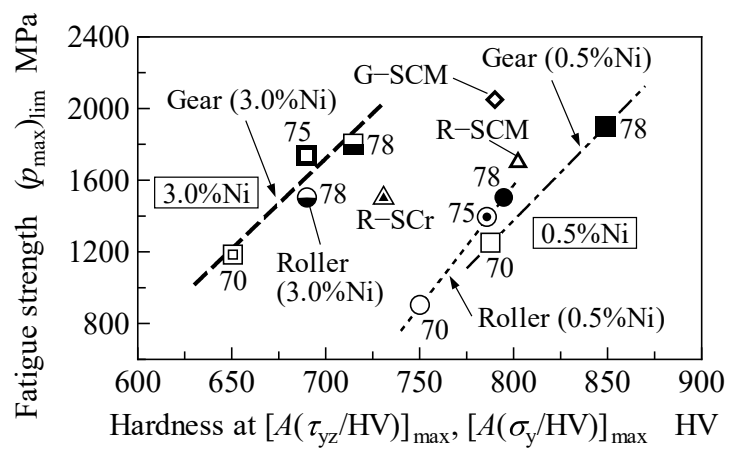

Fig.10 Relationships between fatigue strength and hardness of test rollers and pinions. The fatigue strength of the test specimens was proportional to the hardness at the maximum amplitude for both nickel contents of $0.5 \%$ and $3.0 \%$. In other words, the fatigue strength of the test specimens increased with increasing hardness at the failure depth.

\section{Conclusions}

In order to investigate the influence of density and nickel content on the fatigue strength of sintered and powder-forged gears, sintered and powder-forged rollers and gears with densities in the range $7.01 \mathrm{~g} / \mathrm{cm}^{3}$ to $7.84 \mathrm{~g} / \mathrm{cm}^{3}$ and nickel contents of $0.5 \%$ and $3.0 \%$ were fatigue-tested using a roller testing machine and a gear testing machine. In addition, ingot steel rollers and gears were fatigue-tested for comparison with the results of the sintered and powder-forged ones.

Most of the pores existing in the sintered material became small after hot forging under a compacting pressure, resulting in a forging density of $7.50 \mathrm{~g} / \mathrm{cm}^{3}$. At a forging density of $7.84 \mathrm{~g} / \mathrm{cm}^{3}$, all the pores disappeared below the material surface. The hardness near the surface of the test roller and pinions with a nickel content of $3.0 \%$ was lower than that of the other rollers and pinions. The failure mode of the test rollers was mainly spalling due to subsurface cracking, and that of the test pinions was mainly pitting due to surface cracking. The results of the fatigue tests indicated that the fatigue strength of the test rollers and pinions increased with increasing density. The fatigue strength of the powder-forged rollers and pinions was roughly equivalent to that of the ingot steel ones. Additionally, the fatigue strength of the test rollers and pinions increased with increasing hardness at the failure depth for nickel contents of $0.5 \%$ and $3.0 \%$. The fatigue strength of the test rollers and pinions with a nickel content of $3.0 \%$ was similar to that of the others because of the toughness effect of nickel under the same material density. Therefore, near net shape and net shape manufacture processes should be selected for producing steel gears after carefully examining the forging density and hardness of the powder-forged steel.

\section{Acknowledgment}

The authors would like to thank Kobe Steel, Ltd. for supplying the test specimen and JXTG Nippon Oil \& Energy 
Corporation for supplying the lubricating oil.

\section{References}

Dawson, P. H., Further experiments on the effect of metallic rolling surfaces, Proceedings of the Institution of Mechanical Engineers, Vol.180, No.3B (1965-1966), pp.95-100.

Dowson, D., Elastohydrodynamics, Proceedings of the Institution of Mechanical Engineers, Vol.182, No.3A (1967-1968), pp.151-167.

Engström, U., Fordén, L., Bengtsson, S. and Bergström, M., Surface densification and warm compaction lead to greater density in PM gears, resulting in higher strength and improved fatigue properties, Gear Solutions, Vol.July-2006 (2006), pp.18-22.

Fujita, K. and Yoshida, A., Surface durability of steel rollers (In the case of case-hardened and of nitrided rollers), Bulletin of the JSME, Vol.21, No.154 (1978), pp.761-767.

Fujita, K. and Yoshida, A., Surface failure of soft and surface-hardened steel rollers in rolling contact, WEAR, Vol.55, No.1 (1979), pp.27-39.

Jandeska, W. F., Slattery, R. H., Hanejko, F. J., Rawlings, A. J. and King, P., Rolling-contact fatigue: Performance comparison of surface-densified, powder-forged, and wrought steels, International Journal of Powder Metallurgy, Vol.42, No.1 (2006), pp.57-64.

Japan Society of Mechanical Engineers ed., Gear Strength Design (1979), p.10, Japan Society of Mechanical Engineers (in Japanese).

Johnson, K. L., Contact Mechanics (1987), p.84, Cambridge University Press.

Koide, T., Fukai, Y., Takemasu, T. and Miyachika, K., Ultraprecision micromilling technology, Transactions of the Japan Society of Mechanical Engineers, Series C, Vol.77, No.775 (2011), pp.591-596 (in Japanese).

Li, Z., Wang, B., Ma, W. and Yang, L., Comparison of ironing finishing and compressing finishing as post-forging for net-shape manufacturing, International Journal of Advanced Manufacturing Technology, Vol.86 (2016), pp.33333343.

Seki, M., Yoshida, A., Ohue, Y., Hongo, T., Kawamura, T. and Shimoyama, I., Influence of shot peening on surface durability of case-hardened steel gears, Journal of Advanced Mechanical Design, Systems, and Manufacturing, Vol.1, No.4 (2007), pp.518-529.

Smith, J. O. and Liu, C. K., Stresses due to tangential and normal loads on an elastic solid with application to some contact stress problems, Transactions of ASME, Vol.20, No.2 (1953), pp.157-166.

Stephenson, T. F., Campbell, S. T. and Singh, T., Finer powder additions can make harder, tougher steels, Metal Powder Report, Vol.59, No.3 (2004), pp.26-28, 30.

The Society of Materials Science ed., Standard Method for X-Ray Stress Measurement (1982), p.4, The Society of Materials Science.

Yamanaka, M., Matsushima, Y., Miwa, S., Narita, Y., Inoue, K. and Kawasaki, Y., Comparison of bending fatigue strength among spur gears manufactured by various methods, Journal of Advanced Mechanical Design, Systems, and Manufacturing, Vol.4, No.2 (2010), pp.480-491.

Yonetani, S., On the method of measurement of residual stress in a hollow cylinder by X-ray method, Journal of The Society of Materials Science, Japan, Vol.18, No.90 (1969), pp.610-614 (in Japanese).

Yoshida, A., Ohue, Y. and Karasuno, I., Surface failure and durability of induction-hardened sintered powder metal rollers and gears with various hardened depths, Transactions of the ASME, Vol.116, No.3 (1994), pp.730-737.

Yoshida, A., Seki, M., Ohue, Y., Gotoda, Y. and Hayashi, D., Effect of shot peening on pitting strength of case-hardened steel roller, JSME Annual Meeting, Vol.2003, No.4 (2003), pp.19-20 (in Japanese).

Zhang, Q., Seki, M., Ohue, Y., Yoshida, A., Murakami, M., Sato, M. and Konishi, M., Study on surface durability of powder-forged rollers with case-hardening, JSME International Journal, Series C, Vol.47, No.3 (2004), pp.925932 . 